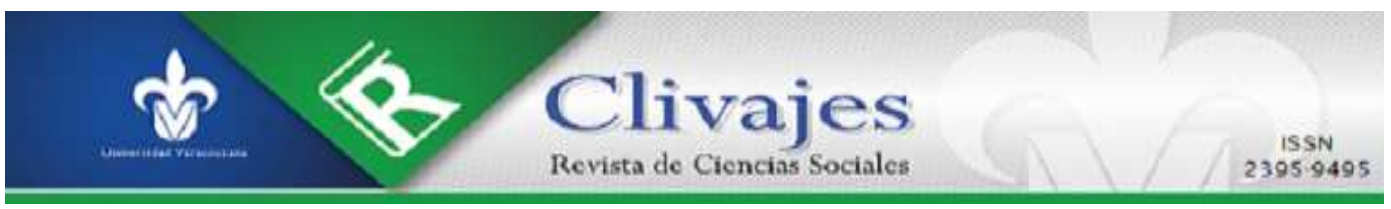

José Galindo Rodríguez

REFLEXIÓN HISTÓRICA SOBRE LOS NOMBRAMIENTOS DE HEROÍSMO:

El caso de Veracruz, "Cuatro Veces Heroica”

Clivajes. Revista de Ciencias Sociales. Año VI, número 11, enero-junio 2019, pp. 41-60.

http://clivajes.uv.mx/index.php/Clivajes/editor/proofGalley/2573/4447

Instituto de Investigaciones Histórico-Sociales, Universidad Veracruzana

Recibido: 08-01-2019

Aceptado: 25/02/2019

Dictaminado: 30/05/2019

Publicación: 29/05/2019 


\title{
REFLEXIÓN HISTÓRICA SOBRE LOS NOMBRAMIENTOS DE HEROÍSMO: El Caso de Veracruz, "Cuatro Veces Heroica”
}

\author{
José Galindo Rodríguez
}

\begin{abstract}
Resumen
En el año de 1948, siendo presidente de México, Miguel Alemán Valdés, y gobernador interino de Veracruz, Ángel Carvajal Bernal, la Legislatura estatal expidió el decreto número 73, declarando "Cuatro Veces Heroica" a la ciudad de Veracruz, por haber tenido lugar ahí cuatro de los sucesos más importantes en la defensa de la soberanía nacional, en los que la población luchó "heroicamente" contra invasores extranjeros. Este ensayo busca analizar algunos aspectos clave de los acontecimientos que condujeron a cada nombramiento; destaca los mitos tras dichos acontecimientos y el sentido de tales nombramientos y analiza, finalmente, las maneras en las que el poder público ha utilizado los nombramientos para alcanzar metas específicas de política y control público, y algunos de sus efectos sobre las instituciones formales del país.
\end{abstract}

Palabras clave: Heroísmo, Historia oficial, Mitos

\section{INTRODUCCIÓN}

En una visita al Museo Histórico Naval en el Puerto de Veracruz se me obsequió un ejemplar del periódico El Dictamen, titulado "Conmemoración del Centenario de la heroica defensa del Puerto de Veracruz ante la invasión norteamericana 1914-2014”. Dada la relevancia del tema, decidí publicar la portada en una red social. A los pocos minutos, un historiador extranjero la compartió en otra red, acompañada de un breve comentario y la pregunta: “QQué opinan?”. Claramente cuestionaba el asunto del heroísmo. En ese momento, su intervención me hizo reflexionar acerca de varios aspectos. En primer lugar, sobre cuál era el sentimiento que generaba entre los estudiosos y otros interesados el hablar de la defensa del Puerto de Veracruz en 1914, calificándola como heroica; la interrogante del mencionado colega me hizo cuestionarme sobre el verdadero valor de otorgar este tipo de nombramientos, es decir, ¿cuáles son las ventajas y desventajas de

\footnotetext{
* Investigador de Tiempo Completo en el Instituto de Investigaciones Histórico-Sociales de la Universidad Veracruzana; miembro del Sistema Nacional de Investigadores, Nivel 1. Licenciado en Economía, por el Instituto Tecnológico Autónomo de México; Master of Philosophy in Latin American Studies. Cuenta con las especialidades: Historia y Desarrollo Económico Latinoamericano e Historia de México en el Siglo XX, por la Universidad de Oxford; es Doctor en Historia, por la Universidad Nacional Autónoma de México, y Postdoctor, por el Departamento de Historia de la Universidad de California, Berkeley.
} 
hacerlo? Esto, sin cuestionar que en efecto existió un breve movimiento ciudadano espontáneo de defensa, además de las limitadas acciones que, con el mismo fin, emprendieron las autoridades mexicanas. En segundo lugar, derivado de lo anterior, reflexioné sobre la imagen que se transmite al exterior con este tipo de nombramientos que, muchas veces, para el caso mexicano, han surgido de la debilidad y de la derrota, sin, por ello, dejar de reconocer que México no es excepcional en cuanto a decretar nombramientos que exaltan sucesos o personajes históricos en ciertos momentos en la historia.

De esta experiencia, formulé un par de preguntas iniciales a las que intentaré dar respuesta en este ensayo: ¿Qué mencionan las fuentes sobre lo que sucedió en estos cuatro episodios históricos? y ¿cómo deben entenderse estos últimos? Tales cuestionamientos me han obligado a profundizar en las historias individuales de los sucesos que llevaron a los nombramientos de heroísmo y a plantear una serie de razonamientos teóricos que han permitido realizar un análisis más profundo.

\section{ASPECTOS CLAVE DE LAS NARRACIONES OFICIALES DE LOS CUATRO EPISODIOS HISTÓRICOS}

La primera de las cuatro ocasiones en las que Veracruz fue declarada heroica sucedió después de la expulsión, en 1825, de las últimas fuerzas españolas que aún mantenían en su poder la fortaleza de San Juan de Ulúa desde el año de la Independencia de México (1821). Las hostilidades entre las fuerzas españolas y las autoridades mexicanas se recrudecieron entre los años 1823 y 1825, año en el que las fuerzas navales de México lograron la capitulación de los españoles en Ulúa, el 23 de noviembre de 1825. El nombramiento de heroísmo, en esa ocasión, se realizó por decreto del congreso local, el 29 de junio de 1826. Se otorgó específicamente a raíz de la defensa ante el violento cañoneo que inició el 25 de septiembre de 1823 y concluyó el 13 de octubre del mismo año y durante el cual, de acuerdo con el cronista José Peña (1957): "se dispararon contra la injustamente castigada Veracruz unos 6,000 tiros de bala rasa, de calibre 36 y 24, y 400 balas de 4 pulgadas.” (p. 6). Sobre este suceso, el mismo cronista narra que "el tremendo ataque al que fue sometido Veracruz, así como la heroicidad de sus hijos, jamás desmentida, tuvieron la recompensa merecida y reconocimiento amplio de todos los mexicanos casi tres años después cuando se expidió el decreto mencionado" (Peña, 1957, pp. 6-7).

Hasta ahora, ni en las narrativas oficiales de los hechos ni en otras fuentes se ha podido localizar cifras de muertos o de involucramiento de los habitantes del Puerto, 
aspectos fundamentales para poder hablar de heroísmo en la población. ${ }^{1}$ En otras palabras, no existen indicios claros de papel alguno, jugado por los pobladores del Puerto de Veracruz como reacción al violento cañoneo. En este caso, pudieron haber sido más los daños materiales sufridos los que llevaron a reconocer a la ciudad. Sobre este aspecto, algunas narraciones mencionan que el bombardeo redujo "los principales edificios a humeantes escombros." También periódicos de la época de la Ciudad de México citan a medios de "Jalapa", afirmando que el General Francisco Lemaur, español al mando de la fortaleza de San Juan de Ulúa, después de haber hecho todo el daño posible a la ciudad de Veracruz, "se estaba bárbaramente divirtiendo en hacer fuego á las recuas que salen cargados con efectos de Veracruz" (Águila Mexicana, $1^{\circ}$ de noviembre, 1823, p. 3).

Un segundo nombramiento de heroicidad hacia la ciudad de Veracruz se realizó a raíz de que, el 28 de noviembre de 1838, el Fuerte de San Juan de Ulúa y el Puerto enfrentaron los ataques de la armada francesa, bajo las órdenes del contralmirante francés Carlos Baudín, en lo que se llamó la "Guerra de los Pasteles". Sobre este hecho, las narraciones oficiales generalmente afirman que la ciudad hizo frente al ataque con dignidad y valentía, lo cual le valió el segundo título de "heroica". En el libro Veracruz Cuatro Veces Heroica (Peña, 1957) se menciona un dato interesante, y es que el mismo jefe de la guarnición de Ulúa, el general Antonio Gaona, en el parte de novedades que rindió al general Manuel Rincón, comandante militar al cual reportaba, narra "el mal estado en el que se hallaba el armamento y la escasez de municiones para mantener un fuego sostenido de piezas de grueso calibre, que consume mucha pólvora” (pp. 9-10).

En este mismo sentido, el periódico El Cosmopolita (5 de diciembre de 1838), señala al respecto que "el sitio no tenía el número necesario de artillería" y que "ni la pólvora era buena, ni la había en la fortaleza en cantidad necesaria: que balas occidadas (sic) y carcomidas por el clima y por el tiempo, jugaban entre los cañones, y que no había ni cureñaje de repuesto” (p. 2). Ante esta situación, en el parte de novedades de Gaona a Rincón, el primero afirma que "no me quedaba otro arbitrio que reducirme a lo que había, y esperar el resultado fatal de una defensa, que sin los elementos necesarios, aunque fuera honrosa, no podía dar gloria a las armas de la república” (Peña, 1957, pp. 9-10). Por otra parte, en periódicos nacionales el mismo general Rincón despertaba dudas de su capacidad de hacer frente al enemigo: "Es respetable el Sr. Rincón, y no dudamos que sabrá morir

\footnotetext{
${ }^{1}$ Además del ya citado libro de José Peña, Veracruz Cuatro Veces Heroica, existen otras narraciones en libros oficiales hechas por encargo del H. Ayuntamiento de la ciudad de Veracruz. Por ejemplo, la titulada Veracruz Cuatro Veces Heroica: ¿Cómo? ¿Cuándo? ¿Por qué?, de Honorio Morales Fernández, publicada en 1991.
} 
con honor, pero la nación y las circunstancias ecsigen (sic) allí un prestigio de más" (El cosmopolita, 28 de noviembre de 1838, p. 4).

Estas líneas, más que generar en cualquier lector crítico sentimientos o pensamientos sobre el heroísmo de los defensores, transmiten una idea de sacrificio. José Peña (1957) continúa narrando el destino de algunos de los involucrados mexicanos en este suceso a través del parte de novedades rendido por Antonio Gaona a Manuel Rincón: "los que no murieron quedaron heridos o contusos". "A las cuatro horas y media de fuego sostenido, la mitad de nuestra artillería estaba desmontada, siéndolo casi en su totalidad la de los baluartes de la línea exterior, que fueron abandonados por esta causa". "Muchos de los nuestros, heridos o contusos... no pudieron ser atendidos por el fuego activo que lo impedía". "Me decidí, pues, con anuencia de los jefes principales de la guarnición, a pedir al Vicealmirante francés una corta suspensión de fuegos, para recoger los heridos y sepultar los muertos" (pp. 9-10). Finalmente, las fuerzas francesas aceptaron el cese al fuego, con la condición de que la guarnición mexicana capitulara, lo cual ocurrió a las 2:00 de la mañana del 28 de noviembre de 1938, siendo ocupada la fortaleza de Ulúa por los franceses ese mismo día a las 12:00 horas.

En el libro de José Peña, ya considerado un texto oficial, menciona que "mucho se criticó al gobierno de don Anastasio Bustamante que durante el bloqueo francés, en siete meses y doce días, no había facilitado a Gaona ni aún lo indispensable para poner los puntos de combate en buen estado para la defensa” (Peña, 1957, p. 11). Por su parte, El Cosmopolita (28 de noviembre de 1838, p. 3) afirmaba lo siguiente: "No podemos creer que sea cierto que el Sr. Bustamante y su gabinete estén persuadidos de que vamos a sostener una guerra", refiriéndose a la inactividad del gobierno nacional ante el suceso. De igual forma, en esos momentos la prensa expresaba ideas como: "En México se sabe que el enemigo está en Veracruz y las mejores tropas se envían a Tampico para atacar otros asuntos de menor importancia" (El Cosmopolita, 12 de diciembre de 1838, p. 4). Lo anterior muestra que no existió el apoyo necesario de los gobiernos para la defensa de Veracruz en ese momento, pero, como analizaremos a detalle más adelante, sí existió el apoyo oficial al nombramiento de heroísmo unos años después, en beneficio de los fines oficiales, lo que también sucede en el caso de los otros episodios aquí narrados.

Finalmente, Baudín ordenó la retirada de las fuerzas francesas a principios de diciembre de 1838. ¿Cuál es entonces el heroísmo celebrado en esta situación? ¿Se puede calificar como un "heroísmo a la mexicana", definiéndolo, en este caso, como el enfrentar al enemigo sin armamento funcional ni preparación técnica, sin estrategias formales para hacerlo y en un entorno de falta de apoyo de las autoridades gubernamentales? Es decir, si 
bien es cierto que eventualmente las fuerzas francesas cedieron ante un mayor número de mexicanos que se acercaron a combatir a favor de México de manera aleatoria y desorganizada, no hubo ninguna planeación estratégica ni liderazgo perceptible de confrontación al enemigo.

El tercer episodio que considera a la ciudad de Veracruz como heroica se refiere al ataque naval y terrestre que recibió el Puerto el 22 de marzo de 1847. En esta ocasión por la escuadra norteamericana al mando del general Winfield Scott. Cito algunas de las versiones oficiales que afirman aspectos absolutamente cuestionables y, por tanto, denotan la construcción de los mitos de los que hablaremos desde una perspectiva teórica más adelante. Por ejemplo, en el artículo "Porque Veracruz es 4 veces heroico" (Yáñez, 2013), publicado en el diario El Universal Veracruz, se afirma que "la ofensiva fue soportada estoicamente por toda la población, aunque la superioridad bélica del invasor terminó por imponerse sobre la maltrecha guarnición que defendía la ciudad, a la que esta acción le valió su tercer título de heroica”. El ya mencionado José Peña (1957) señala que los invasores llegaban a aproximadamente 12,325 hombres, y que Veracruz estaba solamente defendido por 4,930, "con armamento muy inferior. Sin embargo, lucharon denodadamente y con gran valor, los nuestros, en medio del más horrible de los bombardeos" (p. 13).

Lo interesante es que las mismas narraciones, hechas por encargo del Ayuntamiento de Veracruz, reconocen que "al gobierno provisional de don Mariano Salas, poco le preocuparon estos clamores, llegando al grado de concentrar en la capital a los más competentes artilleros, Mariano Aguado y Juan Zamora, únicos militares técnicos con que se contaba para la defensa" (Peña, 1957, p. 13). El Monitor Republicano (28 de marzo de 1847, p. 3) también da cuenta de este hecho: "Pero si es tan satisfactorio para los mexicanos el comportamiento de los defensores de la heroica ciudad, es vergonzosa, detestable, la conducta de los que nos han abandonado en circunstancias tan angustiadas. No parece si no (sic) que el estado de Veracruz es un cuerpo extraño a la confederación mexicana".

En realidad, el Puerto carecía de elementos indispensables para enfrentarse a un enemigo considerablemente superior en todo: número, disciplina y armamento. Sin embargo, en la tradición principalmente de los gobiernos mexicanos por construir mitos provenientes de la moral de los vencidos, los narradores oficiales, como el ya mencionado Peña (1957), nos dicen que "la plaza de Veracruz, sembrada de cadáveres y heridos, humeante y derruida, capituló con honor y gloria, cuando ya no había ni un solo proyectil 
que disparar y ni un solo bocado que llevarse a la boca. Pero Ulúa se mantuvo firme un día más, hasta que ya no fue posible resistir" (p. 14).

El segundo y el tercer títulos de heroísmo de la ciudad de Veracruz los concedió la legislatura local, en diciembre de 1900. La cuarta "H”, como se le llama comúnmente a cada uno de estos episodios de "heroísmo", se declaró, como se mencionó anteriormente, por decreto expedido por la legislatura local de Veracruz en 1948. En algunas fuentes históricas se afirma que este último decreto fue expedido por la presidencia de la República. Sin embargo, únicamente se encontró el de la legislatura del estado de Veracruz. Lo que es un hecho es que sobre todos los nombramientos encontrados, el gobierno federal ha otorgado condecoraciones relacionadas con los hechos heroicos.

El cuarto nombramiento de la ciudad de Veracruz como heroica es producto de una nueva invasión norteamericana sobre el Puerto de Veracruz, la cual tuvo lugar los días 21 y 22 de abril de 1914. El narrador oficial, José Peña (1957), afirma que esta invasión enfrentó principalmente a grupos de civiles voluntarios y cadetes de la escuela naval militar, "que intentaron defender a la nación". Su narración que ha hecho más valiosa esta "defensa mítica" del Puerto afirma que quien era comandante general del puerto de Veracruz en ese momento, Gustavo A. Mass, abandonó el Puerto el 21 de abril, a media tarde, para evitar el derramamiento de sangre, dejando la ciudad abandonada a sus propias fuerzas. El comandante, como narran los estudios del Ayuntamiento, dejó solamente a 180 soldados, con el objetivo de resguardar el equipo que se encontraba en el cuartel militar. Sin embargo, ante la presencia física del enemigo en el territorio de Veracruz:

se organizó rápidamente la defensa, contando con dispersos elementos del 19vo batallón en línea, numerosos voluntarios que había instruido militarmente el patriota coronel don Manuel Contreras, los artilleros de la batería fija, ubicada frente a nuestro glorioso Colegio Preparatorio y súbditos españoles que espontáneamente ofrecieron sus valiosos servicios. Entre los artilleros estaba el héroe José Azueta, quien manejó valientemente su ametralladora, hasta caer acribillado por las balas enemigas (Peña, 1957, p. 17).

En realidad, había muy poco que hacer ante esta invasión norteamericana. Si en otras invasiones había existido alguna posibilidad de generar algún daño al enemigo, en 1914 esta posibilidad era nula. El Imparcial (24 de abril de 1914) señala que el ex gobernador de Minnesota, John Lind, enviado en una misión confidencial a México, le expuso al presidente norteamericano: "No hay ni mil soldados en Veracruz [...] la tripulación sola de uno de nuestros barcos que baje a tierra bastará para ponerlos en fuga; 
carecen de armas y su espíritu está muy debilitado por una larga y sangrienta guerra intestina” (p. 9).

La visión oficial sobre los nombramientos de heroísmo veracruzano se puede resumir en la narración de Peña (1957): "las cuatro insignes haches [...] atestiguan la suprema heroicidad de sus hijos, caídos en el fragor del combate, con la cara al Cielo y el pecho al enemigo" (p. 19). Esta visión también se manifiesta en declaraciones de algunos generales de la época, como la de Manuel Doblado, reconocido militar, abogado y político mexicano de la segunda mitad del siglo XIX:

México hará justicia a todas las peticiones justas y fundadas en el derecho de gentes, pero defenderá hasta el último extremo su independencia y soberanía, y sin aceptar nunca el papel de agresor, que nunca ha tenido, repelerá la fuerza con la fuerza y defenderá hasta derramar la última gota de sangre mexicana en las dos grandes conquistas que el país ha hecho en el presente siglo: La Independencia y la Reforma (Memoria Política de México, 1999).

De la consulta de fuentes realizada, se encontró que la única otra ciudad a la que también ha sido otorgada la distinción de cuatro veces heroica, además de Veracruz, es Puebla. El 10 de mayo de 2013, el congreso local de Puebla emitió el dictamen por el que se declaró cuatro veces heroica a la capital poblana, Puebla de Zaragoza, destacando la batalla del 5 de mayo en contra de los franceses, en la que Puebla tuvo 62 días de asedio por parte de las fuerzas invasoras provenientes de Francia. Los otros hechos que le dieron el nombramiento a esta ciudad fueron el Sitio de Puebla del 16 de marzo de 1863, la Toma de Puebla del 2 de abril de 1867 y la Cuna de la Revolución Mexicana del 18 de noviembre de 1910. Más adelante reflexionaremos brevemente sobre este nombramiento.

\section{EL HEROÍSMO EN LA HISTORIA DEL PAÍS}

En su libro Historia y Celebración, Mauricio Tenorio (2009), estudioso contemporáneo de las celebraciones de México, afirma que “cada mito nacional podría ser desmantelado, empírica y lógicamente, con manotazos de historiador mala leche...” (p. 123). Sin embargo, de acuerdo con Tenorio no existe razón para tal desmantelamiento, ya que eso no detendría la formación de nuevos mitos de igual sustancia y tamaño. El autor menciona que detrás de la construcción de mitos existen rutinas que representan la energía que ha estado detrás de la construcción de la historia del México independiente. Sin detenerse en el detalle del análisis de las rutinas, salvo en la última, Tenorio menciona cuatro 
principales: La rutina occidental vs la no occidental (México es y no es lo que se reconoce como occidental); la de la mezcolanza (la costumbre de analizarlo todo a través del tamiz “México mestizo"); la del choque entre lo tradicional y lo moderno (lo tradicional -a veces obstáculo, a veces paraíso- está siempre en lucha con lo moderno que "siempre es visto cual lo que viene de fuera"); y la que surge de la moral de los vencidos (víctimas). En esta última, es donde se puede encuadrar el mito del heroísmo veracruzano. Tenorio (2009) la describe, diciendo que "los mitos e historias nacionales siempre tienden a regirse por la rutina de la nobleza de ser víctimas de las circunstancias, de los países poderosos [...] de algo o alguien”. Esto es, en parte, producto de que, en palabras del mencionado estudioso, no existen muchas "victorias bélicas que cacarear" (pp. 123-131).

Tenorio invita a repensar el pacto social que es la historia e invita a darle una dirección distinta a estas rutinas mentales. En este sentido, propone analizar si sirven de algo las rutinas mentales expuestas, con el enfoque dirigido a respondernos preguntas acerca de las reglas del juego que aceptamos cumplir, a que estamos dispuestos a someternos como sociedad, y sobre el futuro que se vale imaginar. De ahí, según Tenorio (2009) podría surgir el primer mito nacional "que asuma un país tan occidental como moderno como se puede ser a principios del siglo XXI, cuyo orgullo no es ser mestizo sino aceptar, al menos como principio, la inutilidad de hablar de diferencias étnicas, raciales y culturales y que no es víctima de nada más que de su propia incapacidad de crear y redistribuir bienestar" (p. 131).

Pero, ¿cuál es el origen de los mitos? y ¿por qué son importantes en la historia del país? En su libro Anatomía del Mexicano, Roger Bartra (2002) afirma que fue el atraso, el subdesarrollo y la dependencia (ideológica) lo que movió a que:

surgiesen fuerzas culturales que intentaron favorecer una acumulación intelectual propia, que sustituyese las importaciones, protegida por un mercado ideológico interno acotado por los gobiernos emanados de la Revolución mexicana. Por otro lado, surgieron convicciones de que México albergaba, desde tiempos ancestrales, riquezas y recursos espirituales inagotables que era preciso rescatar, refinar, explotar e incluso exportar a las metrópolis para demostrar que treinta siglos de historia no habían pasado en vano (p. 11).

Varios autores reconocen que la carrera por hacer nación y Estado llevó a reescribir el pasado nacional con sus consecuentes mitos: "el mito es un atributo persistente de muchos nacionalismos territoriales, es ficticio o adoptado; en México es el resultado de transformaciones y erosiones, traídas por la conquista, las migraciones y las invasiones" (Gutiérrez, 2012, p. 43). Existen figuras reconocidas de principios del siglo 
XIX y principios del XX, a las cuales se les atribuye un importante papel en la creación de los mitos del México "independiente" y "revolucionario". Dos figuras importantes del XIX son Fray Servando Teresa de Mier y Carlos María de Bustamante; el primero, en su obra titulada Historia de la Revolución de Nueva España, antiguamente de Anáhuac, o verdadero origen y causas de ella con la relación de sus progresos hasta el presente año de 1813, creó una argumentación política y histórica original a favor de la independencia en la que defiende la causa rebelde. De acuerdo con Enrique Florescano (2002), el argumento de Fray Servando envuelve "el ideario político en un nacionalismo emotivo que recoge tradiciones históricas compartidas por extensos sectores de la población” (pp. 293, 297).

Por otra parte, Carlos María de Bustamante es reconocido por ser creador de numerosos mitos y símbolos nacionalistas que en la actualidad siguen vigentes. Su obra más importante es El cuadro histórico de la Revolución Mexicana, comenzada en 15 de septiembre de 1810 por el ciudadano Miguel Hidalgo y Costilla, Cura del pueblo de Dolores, en el obispado de Michoacán, escrito en forma de cartas, publicado entre 1821-1827. El autor expresa que una de las razones principales para escribirla fue "el grande abandono con que se conducían mis compatriotas en uno de los negocios de que mayor gloria resultaría algún día a nuestra patria... muy poco o casi nada se había impreso de lo que pudiera dar honor a los americanos" (1843, p. 5). En el texto, los personajes del 16 de septiembre de 1810 son héroes importantes; se narran las "gloriosas batallas", los triunfos, las derrotas y “crueldades de la lucha”. Teresa de Mier y Bustamante recogen en sus obras las tradiciones y la historia, tanto indígena -sobre todo, azteca-como criolla, y la lucha de Hidalgo y Morelos por liberar al pueblo de las injusticias de la Colonia, para crear una historia que uniera e integrara a los habitates de un país recién independizado.

Para el siglo XX, las figuras importantes fueron Manuel Gamio, Luis Cabrera y Andrés Molina Enríquez, entre otros autores. El posicionamiento del mestizo como personaje central comenzó con la Independencia, aunque fue la Revolución la que permitió la adopción del mestizo como la raza nacional. Manuel Gamio fue una personalidad primordial en la batalla contra el racismo pseudocientífico (de hecho, las ideas racistas del darwinismo social habían sido derribadas), y es considerado el padre de la construcción del nacionalismo revolucionario (Lomnitz, 2001). Para Gamio, la nación era más un proyecto a construir: el culmen de una historia de división y fractura entre los indígenas y los grupos de origen europeo. Dicho proyecto requería de un amplio programa, pasando por la construcción de una cultura común. Las reflexiones y propuestas de su obra Forjando Patria, fueron una influencia significativa para el ideario del indigenismo mexicano de gran parte del siglo XX. De hecho, este estudio fue clave 
para construir los mitos y los móviles de los mitos que, con el objetivo de cohesionar y manipular a la sociedad, permearon la visión oficial de la historia que aún persiste en algunos aspectos. En palabras de Bartra: “Todavía hoy encontramos rastros de estas corrientes economistas y fundamentalistas, que al menos confluyen en un punto: en su profesión de fe especialista". Sin embargo, para Bartra (2002) "la tragedia del indigenismo de Manuel Gamio radica precisamente en la contradicción que se esconde en el credo especialista: la cultura india, alimento esencial, debía ser devorada y digerida por la modernidad" (pp. 11-12).

En el siglo XX, el sistema político mexicano dominado por el priismo creció a la sombra de su propia idea de la Revolución de 1910. Para Bartra, la explicación de ese misterio político se encuentra en los ámbitos de la cultura, en una compleja trama de fenómenos simbólicos que permitieron la gran legitimidad y estabilidad de un sistema autoritario a lo largo más de siete décadas. Este conjunto de fenómenos simbólicos, Bartra lo define como estructura de mediación, cuyo origen, en el periodo del nacionalismo revolucionario priista, se encuentra, según Bartra (2012) en el mundo agrario y campesino que nació después de la Revolución de 1910: "Esta estructura mediadora, en el campo de la cultura, cristalizó en la formación de la red de imágenes simbólicas que definieron la identidad nacional y el "carácter del mexicano". En esas redes ya no sólo hallamos al campesino, cada vez más ilusorio, creado por el nacionalismo populista, sino diversos actores; en realidad toda una compañía de teatro que escenifica una guerra en gran parte imaginaria" (p. 13).

Sin embargo, sobre la transformación de algunos de los últimos regímenes políticos mexicanos, Bartra (2002) se pregunta si es suficiente una cultura gerencial para dotar de legitimidad a un sistema político democrático: "Se trataría de un sistema legitimado por sí mismo, autónomo y basado en la racionalidad y formalidad de la administración en su capacidad de generar las condiciones políticas de bienestar", lo que representaría el sueño de muchos administradores y tecnócratas. Él mismo responde: no lo creo, "la economía por sí misma no produce legitimidad", "ni siquiera en el dudoso caso de que una cultura semejante trajese el bienestar económico a las amplias capas de la población más desposeída” (pp. 14-15).

Por su parte, en Contra la Historia Oficial, Antonio Crespo (2009) hace una fuerte crítica de los mitos y distorsiones de la historia, sobre todo la que se enseña de manera obligatoria en las escuelas del país. Como afirma Gutiérrez (2012, p. 50): "El Estado es el organismo central del nacionalismo integrador que opera mediante el sistema educativo", y que se encarga de difundir su visión distorsionada y manipuladora por 
medio de los libros de texto, y, en caso de Veracruz, también través de los libros de historia oficial hecha por los cronistas. Crespo condena genéricamente al uso político de la historia. Aunque su libro ha sido criticado de superficialidad y estrechez en su argumentación, Crespo advierte sobre la necesidad de una interpretación del pasado mexicano menos épica y personalista ${ }^{2}$ y sugiere mostrar a los héroes, como lo que fueron, con vicios y virtudes, y a los villanos también: la astucia de Cortés, la crueldad de Hidalgo, el arrojo de Santa Anna, la arbitrariedad de Juárez, la buena voluntad de Maximiliano, la ingenuidad de Madero. Dicho de otro modo, contra toda manipulación política del pasado y el autoritarismo implícito en la noción de una verdad histórica oficialmente sancionada, Crespo concluye proponiendo una "historia oficial para la democracia”, que por definición estaría más apegada a una interpretación más profesional y objetiva de los hechos, y, por lo mismo, sería más democrática, porque retrataría a los próceres en su modesta condición humana, sin el aura de lo sagrado ni de lo maldito, además de que esta historia, en mi visión, se enriquecería si su enfoque se concentrara en los procesos históricos de diversa naturaleza más que en los individuos, mismos que dejarían de jugar un papel central y protagónico en los textos. Es decir, los libros de texto podrían absorber muchos de los avances historiográficos que se realizan en la academia nacional e internacional de calidad.

Sin embargo, existe una dificultad intrínseca de cualquier sistema político para ser totalmente democrático, de acuerdo con los argumentos de Lomnitz, lo que implica que la construcción de una "historia oficial para la democracia" caería en lo mítico también. Hemos visto hasta ahora que el poder estatal se legitima principalmente por procesos culturales, educativos, morales e informativos que constituyen redes. De hecho, las historias sobre los orígenes son requeridas para propagar sentimientos de afinidad o cercanía en una población heterogénea y sin conexiones. No obstante, Lomnitz afirma que los símbolos nacionales se pueden usar para ignorar o desplazar demandas particulares de grupos o individuos de la sociedad. Por ejemplo, en el siglo XIX latinoamericano, las imágenes de exaltación de la naturaleza y la idealización de un pasado indígena remoto se utilizaron para la exclusión de las opiniones e intereses de grandes proporciones de la población que, se entendía, tenían que ser civilizados,

\footnotetext{
${ }^{2}$ En un artículo publicado en Letras Libres, Carlos Bravo Regidor (2009) amplía el enfoque de Crespo y menciona que hay que utilizar otro tipo de enfoques, más allá de la historia de los héroes y villanos, que permitieran pensar la historia como algo distinto a la sola voluntad de los hombres, y en la que los mexicanos pudieran desempeñar otro papel que el de simples acarreados o víctimas del caudillo en turno. En este sentido, Bravo Regidor propone enfoques institucionales, sociales, económicos, culturales e incluso políticos en un sentido más amplio, para expandir la visión personalista de la historia.
} 
educados, mejorados radicalmente, y, en ocasiones, exterminados. En otras palabras, se emplearon como un mecanismo, según Lomnitz, para silenciar (“silencio”) a parte de la población.

El mismo Lomnitz afirma, por otro lado, que las exaltaciones de la profundidad de la nación ("profundidad") han sido esenciales para el empaquetamiento de proyectos modernizadores, llamando a los posibles disidentes al orden en el nombre de una trayectoria compartida. En las sociedades nacionales, "profundidad” y "silencio" están mutuamente implicados. En este sentido, Lomnitz menciona que ambos factores son los gemelos siameses de la formación del Estado nacional. Y es ésta, precisamente, la dificultad intrínseca de todo sistema político para ser totalmente democrático. La relación entre "profundidad" y "silencio" revela, según Lomnitz, un secreto nacional: la democracia, la soberanía nacional y una administración gubernamental racional no serán nunca completamente obtenibles. En este sentido, es el proyecto modernizador del gobierno o sistema político en turno, el que marca la pauta y la prioridad en la imposición de símbolos y, en su caso, el nivel de autoritarismo necesario para silenciar. Además, según Lomnitz (2001), el Estado nacional: "siempre está envuelto en el trabajo de darle forma a la opinión pública con la ayuda de sistemas rígidos de disciplina y exclusión” (pp. 9-23).

\section{LOS NOMBRAMIENTOS DE HEROÍSMO DE VERACRUZ}

Para el año de 1950, en el prefacio de su libro sobre la cultura nacional mexicana, Octavio Paz advierte que su análisis no corresponde a todos los habitantes de México, sino sólo a un segmento, a aquel que estaba consciente de ser mexicano y al cual el mismo Paz consideraba minoría (Paz, 1969). En su obra Deep México, Silent México, Lomnitz (2002) afirma que esto ya no ocurre en el presente, cuando "ya hay mayor consciencia de ser mexicanos" (pp. 9-23). Sin embargo, condiciones como las de 1950 y, en mucho mayor medida, condiciones como las que se presentaron desde el inicio del México independiente, cuando la segmentación de la nación era muy marcada, han tenido importantes consecuencias políticas, culturales, económicas y sociales, lo que ha llevado, entre otras cosas, al empleo de medidas de carácter público, con el objetivo de cohesionar a la sociedad. De hecho, el nombramiento de Veracruz como cuatro veces heroica ocurre en un periodo que mezcla una clara segmentación de la sociedad de México, como recuerda Paz en el prefacio antes citado, y un nacionalismo mundial 
exacerbado, que se manifiesta en el sistema político mexicano, configurado a la sombra de la Revolución mexicana.

En este sentido, el nombramiento de heroísmo en cuatro ocasiones se entiende, aunque no se justifica, en función del contexto mundial y nacional. ${ }^{3}$ Además, según Lomnitz (2002), las ideas propagadas sobre nacionalismo, a mediados del siglo XX, dieron forma a signos específicos vinculados a lugares de memoria local (pp. 15-26), en el caso de Veracruz, lo que se adecua a la división de la historiografía que, sobre el tema, presenta Benjamín Flores (2000, pp. 115-116):

1. Periodo formativo (1810-1867). Inventar a México

2. Consolidación republicana (1867-1920). Definir a México

3. Nuevo Orden “revolucionario" (1920-1988). Mantener a México

En el periodo formativo, Veracruz recibe su primera "H". Es el periodo en que se inventan México y su historia. El título de la segunda y la tercera "H” se otorga hacia 1900, cuando la historiografía de la época define al país, y la última "H" se ubica en el periodo cuando se quiere mantener a México, una unificación de la sociedad no sólo de Veracruz, ciudad y Estado, sino de todo el país.

Por eso es tan poderoso el tema del heroísmo veracruzano; sin duda, toca las fibras más sensibles de algunos sectores de la población veracruzana. Sin embargo, los sucesos que llevaron a la construcción de mitos de heroísmo, y que a su vez condujeron a los mencionados nombramientos, una vez cumplidos sus fines nacionalistas y de cohesión nacional y local, en un periodo específico que ha permeado hasta la actualidad, y ante la evolución del contexto nacional e internacional, se deben reconstruir, reinterpretar y reescribir en términos más apegados a una versión objetiva de la historia, sustentada en estudios históricos minuciosos, basados precisamente en la consulta amplia de fuentes históricas, es decir, en la dirección de lo que, entre otros, plantean Luis González de Alba en Las Mentiras de Mis Maestro (2002) o José Antonio Crespo en Contra la Historia Oficial.

\footnotetext{
${ }^{3}$ Luis Villoro, en su libro Estado Plural, Pluralidad de Culturas (1998) hace una definición de nacionalismo que nos ayuda a probar este punto: "En los nacionalismos, la concepción del Estado-nación como una unidad homogénea en lo interior y excluyente hacia el exterior se sublima en la proyección de esa entidad colectiva en la esfera del valor. Para todo nacionalismo, el Estado-nación encarna valores que ni la vida aislada de cada individuo ni la de un grupo podrían por sí solas alcanzar. La vida personal se transfigura al contribuir a la gloria, al honor, al poder y la virtud de su nación. La entrega a esos valores se justifica en el entusiasmo colectivo. La vida de cada ciudadano se eleva a alturas insospechadas al ser sacrificadas por la patria. El don del individuo a la nación se considera un deber $<$ sagrado $>$. El nacionalismo eleva el sentimiento de pertenencia del individuo a la nación a una unión casi mística; es un sucedáneo laico de las vías religiosas de acceso a lo sagrado".
} 
Estos autores buscan la deconstrucción de la historia oficial, narrando los diversos episodios de manera distinta ante el cambio de contextos y el avance de los medios de comunicación, considerando siempre la búsqueda de otras formas de cohesión social, nacional y local, más en la dirección de implementar políticas inclusivas que contemplen aspectos culturales, educativos, morales e informativos, y que permitan entretejer redes compuestas por elementos heterogéneos.

Cabe decir que las narraciones sobre los episodios que llevaron a los nombramientos de heroísmo veracruzano están cargadas de elementos que exaltan, de manera exagerada, aspectos heroicos de la población; cuando, en realidad, las causas y condiciones por las que se presentaron estos sucesos respondieron, sobre todo, a la falta de capacidad e irresponsabilidad gubernamental para manejarlos, comenzando por su incompetencia para generar una planeación sólida en defensa de la nación, como lo pudimos constatar en las narraciones del principio de este ensayo.

Todo esto parte, pues, de la inhabilidad política para establecer un gobierno nacional y gobiernos locales fuertes e institucionales al paso de los años. En otras palabras, los cuatro episodios de heroísmo ocurren en un periodo largo, que va desde 1825 hasta 1914, tiempo en el cual no hubo avances institucionales formales (ejército, policías, estructura burocrática, entre otros) ni, tampoco, informales de carácter positivo (costumbres, valores sociales, entre otros) -apegándonos a la definición de institución de Douglass North- ${ }^{4}$ dignos de tomarse en cuenta para hablar de algún tipo de heroísmo. Es decir, el no haber generado un avance institucional suficiente para haber combatido al enemigo, o, al menos, planeado adecuadamente algún tipo de defensa, en la línea de una nación que está en un verdadero proceso de consolidación institucional ante el paso del tiempo, es más bien un signo de fracaso y no de heroísmo.

Leer ciertas narraciones heroicas, por ejemplo, los casos de la muerte heroica de José Azueta o la defensa de la Heroica Escuela Naval Militar por parte de sus cadetes, en 1914, invita a reflexionar sobre el sinsentido de algunas de estas defensas, que se pueden clasificar como actos viscerales, como es precisamente el caso de Azueta, o la voluntad genuina, quizás patriótica, pero suicida, de defensa de los pocos otros locales involucrados. En ese sentido, es entendible el sentimiento despertado en algunos mexicanos, exaltado

\footnotetext{
4 "Las instituciones son las reglas del juego en una sociedad o, más formalmente, los constreñimientos u obligaciones creados por los humanos que le dan forma a la interacción humana. En consecuencia, éstas estructuran los alicientes en el intercambio humano, ya sea político, social o económico. El cambio delinea la forma en la que la sociedad evoluciona en el tiempo y es, a la vez, la clave para entender el cambio histórico”. North, Institutions, 1990, p. 3.
} 
por los nombramientos oficiales, de honrar a estos pobladores, que no vieron otra alternativa que combatir a un enemigo muy superior, militarmente hablando, y dejaron su vida por un territorio que seguramente apreciaban.

Sin embargo, los nombramientos provienen de iniciativas gubernamentales, es decir, del grupo de la sociedad que quizás más pecó de omisión ante estos sucesos. Los mismos gobiernos son los que posteriormente han sacado partido del sacrificio aislado de unos vulnerables soldados, marinos y pobladores locales, otorgando nombramientos con finalidades de diversa índole. Nombramientos que, además, siguen exaltándose y celebrándose de la misma manera que en los tiempos cuando sí cumplían con su función de cohesión social. Por ejemplo, un ex presidente de la republica declaró recientemente que:

La gesta heroica de Veracruz representa uno de los episodios más honorables y gloriosos de nuestras Fuerzas Armadas... En esta lucha memorable, el Teniente José Azueta y el Cadete Virgilio Uribe dieron ejemplo de las más elevadas virtudes cívicas y militares... Los jóvenes cadetes que pelearon el 21 de abril de 1914, se convirtieron en héroes porque, no obstante la adversidad, lucharon para mantener a México como una Nación libre, independiente y soberana (Peña, 2016).

Es de subrayar que el nombramiento de Veracruz como cuatro veces heroica es una muestra de que los referentes simbólicos varían a escala local, aunque no están exentos de ser adoptados o copiados por otros estados, como es el caso de los ya mencionados nombramientos otorgados al vecino estado de Puebla. El estado de Puebla nombró a su ciudad como Cuatro Veces Heroica, en 2013, aproximadamente 65 años después que la ciudad de Veracruz, y en un contexto totalmente distinto. De Puebla interesa rescatar brevemente el tema de la batalla del 5 del mayo, tan celebrada, que a final de cuentas no limitó, como todos sabemos, el que Francia estableciera un imperio en México. De alguna manera, es la celebración de una victoria parcial que culminó en una derrota final. ¿Por qué sentirse orgullosos y exaltar que se venció a los franceses al menos esa vez? ¿Tan grande es Francia? ¿O tan pequeña es la concepción que los mexicanos tienen sobre sí mismos? O, más bien, ¿por qué seguir destacando este suceso en el contexto actual, con mayor acceso a la información y, por ende, más crítico? México ya no es el mismo que en los años cincuenta del siglo pasado, cuando pocos habitantes estaban conscientes de su condición de mexicanos. En este sentido, utilizar herramientas de exaltación de ciertos sucesos en el presente carece de sentido y puede tener más desventajas que ventajas. Más cabría subrayar los aspectos positivos con los que cuenta el país, que utilizar la mentira como elemento de cohesión social. 


\section{CONCLUSIONES}

En la memoria colectiva de las diversas localidades y regiones de los países, siempre quedan plasmados hechos históricos relevantes. Los nombramientos oficiales de diversa naturaleza sobre éstas - por ejemplo, el reconocimiento de su carácter heroico, como en Veracruzsurgen, en gran medida, de la necesidad gubernamental de generar identidad nacional sentimientos de nacionalismo- y legitimación. Esto se observa claramente en los acontecimientos acerca del supuesto heroísmo veracruzano, mencionados en la primer parte de este artículo, ampliamente divulgados por cronistas oficiales. Como consecuencia, para los gobiernos nacional y local, la principal ventaja de estos nombramientos de heroísmo es que les permitió generar cohesión, lo que, entre otras cosas, ha facilitado la manipulación y, por lo mismo, el control social, al adentrarse en los sentimientos de la población.

Los nombramientos de Veracruz no son aislados; están relacionados con todas las políticas gubernamentales y mitos asociados, con la finalidad de "forjar patria", como es el caso de los Niños Héroes de Chapultepec, la Batalla de Puebla, la construcción ideológica del mestizaje y el vínculo con el pasado indígena y los múltiples mitos sobre la revolución "social" mexicana, así como con todos aquellos aspectos que han sido exaltados en cada uno de los estados de este país. También es importante tomar en cuenta que en el periodo en el que se conceden estos nombramientos de heroísmo veracruzano, en particular, el cuarto nombramiento, a mediados del siglo XX, existe un exacerbado nacionalismo mundial, asociado al periodo nacional-socialista, que imperó en gran parte de los países, además de que en la presidencia del país se encontraba “el hijo predilecto de Veracruz”, Miguel Alemán Valdés.

Se justifica que, en algún momento, los nombramientos hayan tenido su razón de ser, sobre todo cuando no existía conciencia de pertenencia a la nación en gran parte de los pobladores a mediados de la década de 1950. Existen, como en todo, pros y contras de mantener la historia oficial, basada en mitos. En opinión del autor, actualmente existen más contras, en función de que hay mucho mayor acceso a la información que en otros periodos y, en consecuencia, la sociedad es más crítica y se cuestionan "valores" que anteriormente las escuelas y muchos padres inculcaban a los hijos. Además, cada día hay más investigadores en el campo de la historia que sustentan sus investigaciones en más fuentes y les dan mayor divulgación. En este sentido, no hay duda de que la mayor parte de la población, al menos la medianamente letrada, está consciente de que estas ideas de heroísmo locales provienen fundamentalmente de la construcción de mitos, de situaciones 
ficticias lejanas a la realidad, fabricadas por medio de explicaciones breves y con fuentes de información escasas. Así, basar la historia oficial en mitos, deslegitima más de lo que legitima al Estado en nuestros días. Incluso, en el pasado, cuando se ha abusado de este mecanismo de legitimación y cohesión, ha sido muy mal visto: el caso de Carlos María de Bustamante, llamado "mentiroso" por algunos de sus contemporáneos, es un ejemplo de ello.

Por otra parte, en el caso de los nombramientos de heroísmo que se han otorgado ante eventos donde las fuerzas defensoras mexicanas fueron derrotadas, el volver héroes a las víctimas muestra la debilidad del Estado mexicano ante el exterior; o, para los extranjeros más humanos, genera un sentimiento de compasión no muy deseable, independientemente del posible efecto de cohesión interna que estos nombramientos pudiesen tener. Cambiar nuestros planteamientos históricos oficiales, en la dirección de lo que realmente somos y fuimos, representa una posición que puede transformar la percepción que sobre este país se tiene en el exterior, con un enfoque más objetivo, además de sumar positivamente en la dirección del inicio de una reconstrucción institucional sólida, sustentada en criterios más realistas de análisis sobre lo que es México.

Sin embargo, y asumiendo como innegable que es necesario mantener una cultura política basada en signos y símbolos distintos, que den como resultado una estructura mediadora capaz de auspiciar la vinculación entre los distintos grupos e individuos que conforman la sociedad, y sustentada en algo más allá que una cultura de gestión, la propuesta de crear una historia oficial más apegada a la realidad cobra sentido. La idea es aspirar a la comprensión de una historia más cercana a los hechos, tal como sucedieron, que muestre cuanto hemos sido, más que cuanto nos hubiera o no gustado ser. Es evidente que hoy en día, con un sentimiento ya formado de pertenencia a la nación, no es necesario continuar manipulando la historia. Dicho de otro modo, es falso lo que las autoridades asumen, al menos en la práctica, acerca de que desmitificando la historia se perderá cohesión social, y que por desconocer o modificar la verdadera historia de su país, los mexicanos serán mejores ciudadanos.

\section{REFERENCIAS}

Águila Mexicana, $1^{\circ}$ de noviembre de 1823.

BARTRA, R. (2002). Anatomía del Mexicano, Barcelona, España: Plaza y Janés. 
Bravo, C. (2009). Contra la historia oficial, de José Antonio Crespo. México. Letras Libres. Recuperado de: https://www.letraslibres.com/mexico/libros/contra-lahistoria-oficial-jose-antonio-crespo

De Bustamante, C. M. (1843). El cuadro histórico de la Revolución Mexicana, comenzada en 15 de septiembre de 1810 por el ciudadano Miguel Hidalgo y Costilla, Cura del pueblo de Dolores, en el obispado de Michoacán. México: Imprenta de J. Mariano Lara.

Recuperado de:

http: / / cdigital.dgb.uanl.mx/la/1080017737_C/1080017737_T1/1080017737 _MA.PDF

Crespo, J. A. (2009). Contra la Historia Oficial, México: Debate.

Doblado, M. (1862). A los Sres. comisarios de la Gran Bretaña, la Francia y la España. En Dávila, D.C. (Selec.) (1999), Memoria Política de México. Recuperado de: http: / / www.memoriapoliticademexico.org/Textos/4IntFrancesa/1862CGBFE-MD.html

Douglas, N. (1990). Institutions, Institutional Change and Economic Performance. Cambridge University Press.

El Cosmopolita, 28 de noviembre de 1838. , 5 de diciembre de 1838. , 12 de diciembre de 1838.

El Imparcial, 24 de abril de 1914.

El Monitor Republicano, 28 de marzo de 1847.

El Universal Veracruz (2013).

Flores, B. (2000). México en tres tiempo. Una propuesta de periodización de la historiografía mexicana de la etapa independiente. México: Caleidoscopio, 7.

Florescano, E. (2002). Historia de las Historias de la Nación Méxicana, México, Taurus. Gamio, M. (1992). Forjando patria. México: Porrúa.

GuTIÉRreZ, N. (2012). Mitos nacionalistas e identidades étnicas: los intelectuales indígenas y el Estado mexicano. México: UNAM-Instituto de Investigaciones Sociales.

LomnitZ, C. (2001). Deep Mexico, Silent Mexico, Minneapolis: Minnesota University Press.

MartíneZ, A. (1982). La intervención norteamericana, Veracruz, 1914. México: Cultura/Secretaría de Educación Pública, Martín Casillas Editores.

Morales, H. (1991). Veracruz Cuatro Veces Heroica: ¿Cómo? ¿Cuándo? ¿Por qué? México: Editora de Gobierno del Estado de Veracruz.

PAZ. O. (1969) El laberinto de la soledad. México: Fondo de Cultura Económica. 
PeñA, J. (1957). Veracruz Cuatro Veces Heroica, México: Editora de Gobierno del Estado de Veracruz.

Presidencia de México (2016). Palabras del Presidente Enrique Peña Nieto, Jura de Bandera de los Cadetes de 1er. Año Generación 2014-2019. Heroica Escuela Naval Militar. México: Secretaria de Gobernación. Recuperado de: https: / / www.gob.mx/presidencia/prensa/palabras-del-presidente-enriquePENA-NIETO-JURA-DE-BANDERA-DE-LOS-CADETES-DE-1ER-ANO-GENERACION-20142019-heroica-escuela-naval-militar

Tenorio, M. (2009). Historia y Celebración, México: TusQuets Editores.

Teresa DE Mier, J. S. (1922). Historia de la Revolución de Nueva España, antiguamente de Anáhuac, o verdadero origen y causas de ella con la relación de sus progresos hasta el presente año de 1813. México: Imp. de la Cámara de Diputados.

Villoro, L. (1998). Estado Plural, Pluralidad de Culturas, México: Ediciones Paidós. 